\title{
Colon-Specific Delivery of Bioactive Agents Using Genipin-Cross-Linked Chitosan Coated Microcontainers
}

Kamguyan, Khorshid; Torp, Anders Meyer; Christfort, Juliane Fjelrad; Guerra, Priscila; Licht, Tine Rask; Hagner Nielsen, Line; Zor, Kinga; Boisen, Anja

\section{Published in:}

ACS Applied Bio Materials

Link to article, DOI:

10.1021/acsabm.0c01333

Publication date:

2021

Document Version

Peer reviewed version

Link back to DTU Orbit

Citation (APA):

Kamguyan, K., Torp, A. M., Christfort, J. F., Guerra, P., Licht, T. R., Hagner Nielsen, L., Zor, K., \& Boisen, A. (2021). Colon-Specific Delivery of Bioactive Agents Using Genipin-Cross-Linked Chitosan Coated Microcontainers. ACS Applied Bio Materials, 4(1), 752-762. https://doi.org/10.1021/acsabm.0c01333

\section{General rights}

Copyright and moral rights for the publications made accessible in the public portal are retained by the authors and/or other copyright owners and it is a condition of accessing publications that users recognise and abide by the legal requirements associated with these rights.

- Users may download and print one copy of any publication from the public portal for the purpose of private study or research.

- You may not further distribute the material or use it for any profit-making activity or commercial gain

- You may freely distribute the URL identifying the publication in the public portal 


\title{
Colon-specific Delivery of Bioactive Agents using
}

\section{Genipin-crosslinked Chitosan Coated}

\section{Microcontainers}

Khorshid Kamguyan ${ }^{1,}{ }^{*}$, Anders Meyer Torp ${ }^{2}$, Juliane Fjelrad Christfort ${ }^{1}$, Priscila R. Guerra ${ }^{2}$, Tine Rask Licht ${ }^{2}$, Line Hagner Nielsen ${ }^{l}$, Kinga Zor ${ }^{1}$, Anja Boisen ${ }^{1}$

${ }^{1}$ The Danish National Research Foundation and Villum Foundation's Center for Intelligent Drug Delivery and Sensing Using Microcontainers and Nanomechanics, Department of Health Technology, Technical University of Denmark, 2800 Kgs. Lyngby, Denmark

${ }^{2}$ The National Food Institute, Technical University of Denmark, 2800 Kgs. Lyngby, Denmark

Keywords: Chitosan; Genipin; Local delivery; Enzyme-triggered release; Microdevices; Lactobacillus rhamnosus GG

\begin{abstract}
Oral administration of probiotics is beneficial for restoring the intestinal microbial balance and for the treatment of gastrointestinal (GI) tract-related disorders. In the current era characterized by the development of next-generation probiotic microorganisms, which are typically less robust towards
\end{abstract}


environmental challenges than the classically applied lactic acid producing probiotics, we anticipate a need for delivery of live organisms directly to the site where they need to colonize. Here, we thus present, for the first time, a proof of concept for using micrometer-sized polymeric containers, for the engineered delivery of probiotics, using spray dried Lactobacillus rhamnosus GG (LGG), as a model probiotic microorganism. To achieve colon-specific delivery, microcontainers are loaded with LGG and sealed with an enzyme-sensitive coating. A genipincrosslinked chitosan coating is developed that: (i) is stable at gastric and intestinal pH; (ii) has tunable swelling; and (iii) is degradable by the colon-specific bacterial enzymes. The chitosangenipin coated microcontainers are evaluated in vitro, ex vivo as well as in vivo in a rat model. Our results confirm that the genipin-crosslinked chitosan coating enables an effective local delivery in the cecum and colon without any premature release in the small intestine. Our findings suggest that the integration of modified polysaccharides with ingestible microdevices has great potential for controlled and site-specific delivery of live microorganisms.

\section{Introduction}

The colon of a healthy human contains hundreds of distinct species of bacteria, considerably more than other parts of the body ${ }^{1,2}$. Disturbance of the healthy microbiota is associated with chronic illnesses such as inflammatory bowel diseases, in which case the administration of probiotics can be beneficial to eliminate the symptoms or even cure the patient ${ }^{3,4}$. Therefore, encapsulation and targeted delivery of probiotic bacterial strains to the colon have been increasingly studied over the last few decades 5 . However, the delivery systems designed for this purpose face many challenges such as early release of bacteria while passing through the stomach 
and the small intestine, which may reduce viability of bacteria that are sensitive to the conditions in the upper part of the digestive tract ${ }^{6}$. Research into next-generation probiotics is focused on putative applications on a number of alternative microorganisms, many of which are more vulnerable to the environment of the upper GI tract and can benefit from direct delivery to the $\operatorname{colon}^{7-10}$.

Microfabricated devices render a new approach for delivering active compounds to specific sites in the GI tract ${ }^{11-13}$ and have great potential for colon-specific oral delivery of next-generation probiotic organisms ${ }^{14}$. Microcontainers, i.e. polymeric devices for oral drug delivery, are designed and fabricated as a reservoir with an opening on one side, to hold and carry a compound to the target site of release ${ }^{15,16}$. Previous studies have shown that microcontainers can facilitate protection of loaded contents through the various local environments of the GI tract ${ }^{17,18}$, controlled release of pharmaceuticals $^{19,20}$ and their tunable properties can increase the intestinal retention of a drug formulation ${ }^{21,22}$. After fabrication, the microcontainers are loaded with a compound followed by sealing with a polymeric lid ${ }^{23}$. The polymeric lid coating enables further protection of the loaded cargo, modulates the controlled release of the loaded compound, as well as the bioadhesion of microcontainers in vivo ${ }^{24,25}$.

Colon-specific delivery systems are often designed based on stimuli-responsive polymers, sensitive to the physiological characteristics of the $\operatorname{colon}^{26}$. The distinguishable features of the colon in comparison with other sections of the gastrointestinal (GI) tract include: (i) $\mathrm{pH}$ (5.5-7.8 in the small intestine and 5-8 in the colon of healthy fasted humans) $)^{27}$, (ii) transit time (3-4 $\mathrm{h}$ in the small intestine, whereas $24-48 \mathrm{~h}$ in the colon) ${ }^{28}$ and (iii) colon-specific bacterial strains responsible for a high enzymatic activity ${ }^{29}$. Reportedly, transit time and $\mathrm{pH}$ of the different sections of the GI tract are highly variable between individual ${ }^{30}$ and this variability is even more pronounced in 
patients with GI disorders as e.g. ulcerative colitis ${ }^{31}$. Therefore, enzyme-sensitive delivery systems can be more reliable for the development of targeted delivery strategies compared to those triggered by time or $\mathrm{pH}$.

Polysaccharides are mostly digested and fermented by glycosidase enzymes produced by the bacterial genera Bifidobacterium and Bacteroides residing in the $\operatorname{colon}^{32}$. Therefore, these biopolymers have great potential for the development of colon-specific delivery systems, that enable localized release of e.g. probiotics ${ }^{33-36}$. However, as polysaccharides are mostly watersoluble and sensitive to $\mathrm{pH}$ variations throughout the GI tract, they need to be modified to prevent an early release before reaching the colon ${ }^{37,38}$. Chitosan, has been studied for encapsulation and controlled release of probiotics due to its biodegradability in the colon and favorable mucoadhesive properties $^{39-41}$. However, chitosan is highly charged in the acidic environment of the stomach and semi-charged in the intestines, due to the amine functional groups on the backbone of the polymer chain $^{42}$. Therefore, when incorporated into a delivery system, the transported cargo can be released in the fore-colon GI sections. In this regard, it has previously been shown that the release rate of encapsulated compounds can be controlled by crosslinking chitosan using genipin, a natural, biocompatible and non-toxic crosslinker ${ }^{43-45}$. Although genipin has not been approved for commercial use in food or pharmaceutical industries by the U.S. Food and Drug Administration (FDA) or the European Food Safety Authority (EFSA), research studies have shown no significant signs of genotoxic effects e.g. DNA damage in vivo ${ }^{46}$. 


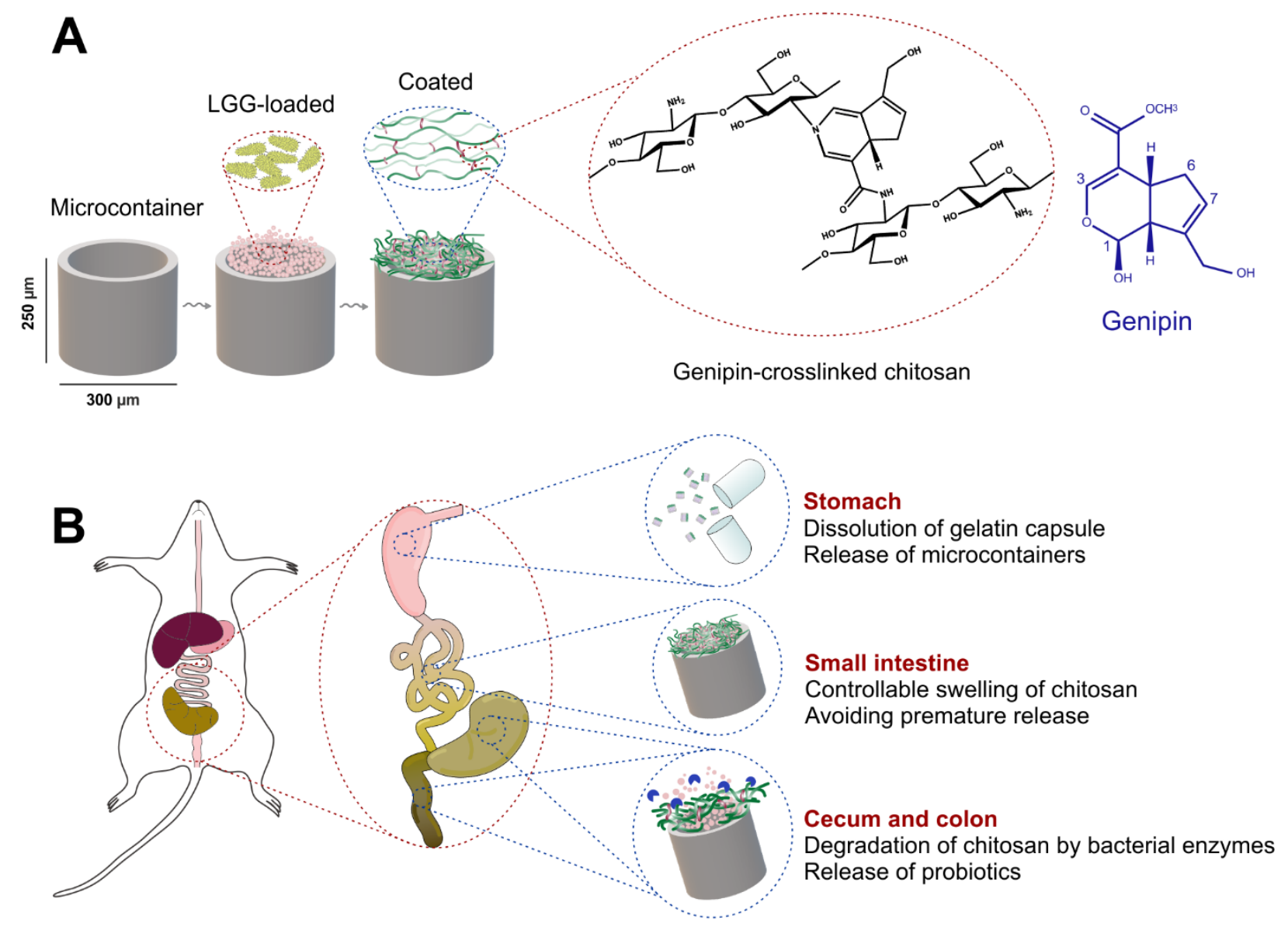

Figure 1. Illustrated concept of the study, comprising of (A) loading probiotics (pink) into microcontainers and deposition of a chitosan-genipin coating (green) and (B) in vivo evaluation of the colon-targeted delivery system in rats triggered by bacterial enzymes (blue).

In this study, we have developed and optimized a micro-sized delivery system for the inoculation of live microorganisms locally into the colon. The well-studied probiotic bacterial strain Lactobacillus rhamnosus GG (LGG) ${ }^{47}$, chosen as a model microorganism due to its robustness and ease of handling, was spray dried and loaded inside microcontainers. Thereafter, the loaded microcontainers were sealed with genipin-crosslinked chitosan to ensure an enzyme-sensitive release in the lower GI tract (Figure 1-A). The delivery system was designed to sustain the release of spray dried LGG through the $\mathrm{pH}$ variations of the stomach and small intestine and facilitate 
local delivery to the colon through biodegradation of the designed polymeric coating (Figure 1B). The performance of the colon-targeted delivery system was evaluated in vitro, ex vivo and in vivo.

\section{Materials and Methods}

\subsection{Materials}

Chitosan (low molecular weight, degree of deacetylation of $76 \%$ and viscosity $(1 \%$ concentration in $1 \%$ acetic acid) of $87 \mathrm{CPS}$, specified by the supplier), skim milk powder, D-(+)trehalose dihydrate ( $\geq 99.0 \%$ ), phosphate buffer saline (PBS), acetic acid ( $\geq 99 \%$ ) and dibutyl sebacate were all purchased from Sigma-Aldrich (St. Louis, MO, USA). Genipin ( $\geq 98 \%$ ) was purchased from Wako Pure Chemical Industries Ltd (Osaka, Japan) and chitosanase derived from Streptomyces species was obtained from Merk Millipore, Calbiochem (Burlington, MA, USA). $ø 100 \mathrm{~mm}$ single-side (thickness $=525 \mu \mathrm{m}$ ) polished silicon $(\mathrm{Si})$ wafers were from Topsil Global Wafers A/S (Frederikssund, Denmark) and SU-8 2035, 2075 and SU-8 developer were purchased from micro resist technology GmbH (Berlin, Germany). Sylgard ${ }^{\circledR} 184$ polydimethylsiloxane (PDMS) elastomer was obtained from Dow Corning (Midland, MI, USA) and Eudragit ${ }^{\circledR}$ L100 (EL-100) was supplied by Evonik (Essen, Germany). Ultrapure water was obtained using a water filtration unit from Millipore Corporation (Billerica, MA, USA), whereas Man/Rogosa/Sharp (MRS) agar plates and MRS bouillon were acquired from SSI Diagnostica (Hillerød, Denmark). Gelatin capsules, size 9 were purchased from Torpac ${ }^{\circledR}$ (Fairfield, NJ, USA).

\subsection{Characterization of genipin-crosslinked chitosan}

A $\mu$-Diss profiler (pION INC, Woburn, MA, USA) was used to characterize the UV-visible spectra of chitosan $(0.5 \% \mathrm{w} / \mathrm{v}$ in $1 \mathrm{mM}$ acetic acid), genipin ( $0.5 \% \mathrm{w} / \mathrm{v}$ in PBS) and monitor 
genipin-crosslinking of chitosan in real time for $24 \mathrm{~h}$. Experiments were performed at room temperature in triplicates, using a UV probe with a $20 \mathrm{~mm}$ path length to monitor a wavelength range between 200 to $700 \mathrm{~nm}$.

A QSense Analyzer (Biolin Scientific, Stockholm, Sweden) with a silica sensor was utilized to perform the quartz crystal microbalance with dissipation monitoring (QCM-D) experiments in flow. To prepare the chitosan-genipin single layer, $0.45 \% \mathrm{w} / \mathrm{v}$ chitosan solution in $1 \mathrm{mM}$ acetic acid containing $2 \mathrm{mM}$ genipin was homogenized using a vortex mixer. The sensor was coated with chitosan-genipin using a WS-650-23B Spin Coater (Laurell Technologies, North Wales, PA, USA) with a speed of 3,000 rpm for $15 \mathrm{~min}$. The coated sensor was kept in a chamber with $80 \%$ relative humidity $(\mathrm{RH})$ for $16-18 \mathrm{~h}$ for completion of the crosslinking process ${ }^{48}$.

The investigation of $\mathrm{pH}$-sensitivity of genipin-crosslinked chitosan was conducted in two different media. Initially, the chambers were filled with $1 \mathrm{M}$ acetic acid $(\mathrm{pH}=2.5)$ for $30 \mathrm{~min}$, followed by PBS ( $\mathrm{pH}=7.4$ ) for 100-120 min. Lastly, the chambers were filled again with $1 \mathrm{M}$ acetic acid. Frequency shifts $(\Delta \mathrm{f})$ and shifts in dissipation $(\Delta \mathrm{D})$ were monitored and recorded for all overtones and plotted for the $3^{\text {rd }}, 5^{\text {th }}$ and $7^{\text {th }}$ overtones as a function of time. All measurements were performed with a $100 \mu \mathrm{L} / \mathrm{min}$ flow rate at room temperature.

\subsection{Culture and spray drying of LGG}

Lactobacillus rhamnosus GG (ATCC 53103) was cultivated on MRS agar plates and incubated at $37^{\circ} \mathrm{C}$ under anaerobic conditions. In order to identify the introduced LGG strain in the nonsterilized contents of the GI tract in the performed ex vivo and in vivo experiments, a rifampicinresistant LGG mutant was used. The spontaneous rifampicin mutation was selected by streaking the wild type LGG, in high concentrations, onto MRS agar supplemented with rifampicin (50 
$\mu \mathrm{g} / \mathrm{mL}$ ). Resistant colonies were checked by a rifampicin gradient, ranging from 50 to $100 \mu \mathrm{g} / \mathrm{mL}$. The selected rifampicin mutant grew on MRS with the same growth rate as the wild type LGG.

A BÜCHI mini spray dryer B-290 (BÜCHI Labortechnik AG, Flawil, Switzerland) was used for spray drying the LGG cultures using a $0.7 \mathrm{~mm}$ nozzle. The LGG cultures were centrifuged at 5,000 rpm for 10 min. Prior to spray drying, the obtained bacterial pellets were re-suspended in an aqueous solution containing $10 \% \mathrm{v} / \mathrm{v}$ of D-(+)-trehalose dihydrate and $10 \% \mathrm{v} / \mathrm{v}$ of skim milk powder. The prepared suspension was then spray dried at $4.5 \mathrm{~mL} / \mathrm{min}$ using an inlet temperature of $100^{\circ} \mathrm{C}$ and an outlet temperature of $60^{\circ} \mathrm{C}$, with $100 \%$ aspirator and a $40 \%$ air flow.

The survival of LGG during the spray drying process was calculated based on the colonyforming units $(\mathrm{CFU}) / \mathrm{mL}$ of the bacteria before and after spray drying. $100 \mu \mathrm{L}$ of samples were serial diluted and plated on MRS agar plates (for wild type LGG) and MRS agar plates supplemented with rifampicin ( $50 \mu \mathrm{g} / \mathrm{mL}$, for rifampicin-resistant $\mathrm{LGG}$ ) and incubated at $37^{\circ} \mathrm{C}$ for $48 \mathrm{~h}$ under anaerobic conditions.

\subsection{Fabrication of microcontainers}

Microcontainers were produced from the epoxy-based negative photoresist, SU-8, similarly to the previously established UV-lithography based fabrication schemes ${ }^{18,49}$. Briefly, a $35 \mu \mathrm{m}$ thick bottom layer (SU-8 2035) was spin coated (RCD8 manual spin coater, Süss MicroTec, Garching, Germany) on Si substrates, which was then subjected to a soft bake at $50^{\circ} \mathrm{C}\left(\right.$ ramping $=2^{\circ} \mathrm{C} / \mathrm{min}$ ) for $2 \mathrm{~h}$. Next, the layer was UV-exposed using a Karl Süss Mask Aligner MA6 (Süss MicroTec, Garching, Germany) in soft contact mode $\left(250 \mathrm{~mJ} / \mathrm{cm}^{2}, 30 \mathrm{sec}\right.$ dwell time) and a post exposure bake at $50^{\circ} \mathrm{C}$ for $6 \mathrm{~h}$. In order to define the sidewalls, a layer of SU-8 2075 was spin coated to obtain a thickness of approximately $220 \mu \mathrm{m}$ and soft baked at $50^{\circ} \mathrm{C}$ for $10 \mathrm{~h}$. The layer was then exposed in proximity mode $\left(2 \times 250 \mathrm{~mJ} / \mathrm{cm}^{2}, 30 \mathrm{sec}\right.$ dwell time). Subsequently, the substrates were 
subjected to a post exposure bake at $50{ }^{\circ} \mathrm{C}$ for $10 \mathrm{~h}$ before developing the SU-8 in two mr-Dev 600 baths with magnetic stirring. The development was done using $2 \times 20$ min immersion followed by flushing with isopropanol and drying. The wafers containing microcontainers were cut into $1.2 \times 1.2$ cm chips using an automatic dicing saw (DAD 321, DISCO, Tokyo, Japan). For the fabrication of the microcontainers used for in vivo experiments, a release layer of $5 \mathrm{~nm}$ Ti and $20 \mathrm{~nm}$ Au was deposited by E-beam evaporation (Temescal, Ferrotec $\mathrm{GmbH}$, Unterensingen, Germany) on the $\mathrm{Si}$ wafers. The release layer facilitated easy detachment of the single microcontainers, which were later filled in gelatin capsules.

\subsection{Loading of LGG into microcontainers and lid deposition}

Microcontainers were loaded with the spray dried LGG using a previously established masking technique ${ }^{50}$. In short, Sylgard ${ }^{\circledR} 184$ two-part (resin and curing agent) PDMS elastomer were mixed with a weight ratio of 10:1 and poured in 25 well chip trays containing the microcontainer chips. The chip trays were kept at $70^{\circ} \mathrm{C}$ for 30 min until the PDMS was fully crosslinked. The masked microcontainers were then loaded using a spatula to press the LGG powder on top of the chips. The excess powder was removed using a soft brush and an air gun. To calculate the amount of powder inside the microcontainers, the masked chips were weighed before and after loading. After loading, the PDMS mask was manually peeled off of the chip using tweezers.

LGG-loaded microcontainers were coated using an ultrasonic spray coater (Sono-Tek, Milton, NY, USA) with an AccuMist ${ }^{\mathrm{TM}}$ nozzle and a heating plate. The spray coating parameters for chitosan (control), chitosan-genipin and EL-100 (control) coatings are provided in Table 2.

Chitosan lids were spray coated using chitosan $0.5 \% \mathrm{w} / \mathrm{v}$ in $1 \mathrm{mM}$ acetic acid, while for the chitosan-genipin lids chitosan $0.45 \% \mathrm{w} / \mathrm{v}$ in $1 \mathrm{mM}$ acetic acid solution containing $2 \mathrm{mM}$ genipin was used. After the chitosan-genipin lid was deposited, the coated microcontainers were kept in 
$80 \% \mathrm{RH}$ for $16-18 \mathrm{~h}$ for completion of the crosslinking process. EL-100 lids were spray coated using an EL-100 1\% w/v in isopropanol solution containing $5 \% \mathrm{w} / \mathrm{w}$ (in relation to the polymer) dibutyl sebacate as a plasticizer.

Microcontainers were characterized post-fabrication, during and after the loading and coating processes using a TM3030Plus tabletop scanning electron microscope (SEM, Hitachi High Technologies Europe GmbH, Krefeld, Germany) with a voltage of $15 \mathrm{keV}$.

Table 1. Parameters used for spray coating polymeric lids onto the loaded microcontainers.

\begin{tabular}{lcc}
\hline Polymers & Chitosan/chitosan-genipin & EL-100 \\
\hline Atomizer pressure $(\mathrm{kPa})$ & 0.01 & 0.02 \\
Nozzle speed $\left(\mathrm{mm} \cdot \mathrm{s}^{-1}\right)$ & 25 & 10 \\
Total No. of loops & 200 & 40 \\
Temperature $\left({ }^{\circ} \mathrm{C}\right)$ & 50 & 40 \\
Generator power $(\mathrm{W})$ & 1.3 & 2.2 \\
\hline
\end{tabular}

\subsection{In vitro and ex vivo release of LGG from microcontainers}

\subsubsection{In vitro release studies}

The release of spray dried LGG from uncoated and coated (chitosan and chitosan-genipin) microcontainers was measured using a $\mu$-Diss profiler (pION INC, Woburn, MA, USA) in $1 \mathrm{M}$ acetic acid for $2 \mathrm{~h}$ and PBS for $12-16 \mathrm{~h}(\mathrm{pH}=2.5$ and 7.4 , respectively). The chips containing the loaded and coated microcontainers were attached to magnetic stirrers in glass vials, filled with 10 $\mathrm{mL}$ of the respective release media. Cumulative release profiles were obtained through monitoring the UV spectrum of skim milk powder present in the spray dried formulation, therefore indirectly measuring the release of the bacteria. The UV spectra of pure skim milk powder and the spray 
dried LGG powder were matched and linear calibration curves were obtained for the second derivative of the UV spectrum at $300 \mathrm{~nm}$ (supporting information S1).

The stability of the chitosan-genipin coatings was studied in conditions simulating the $\mathrm{pH}$, transit time $\mathrm{e}^{51,52}$ and the colonic bacterial enzymes ${ }^{53}$ in the GI tract of rats. The release studies were carried out in $1 \mathrm{M}$ acetic acid $(\mathrm{pH}=2.5)$ for $30 \mathrm{~min}$, followed by changing the release medium to PBS $(\mathrm{pH}=7.4)$ for $3 \mathrm{~h}$, then, the samples were transferred to $10 \mathrm{~mL}$ PBS $(\mathrm{pH}=7.4)$ containing 0.08 $\mathrm{U} / \mathrm{mL}$ chitosanase for $12-16 \mathrm{~h}^{54,55}$.

All experiments were carried out in triplicates at $37^{\circ} \mathrm{C}$ with a stirring rate of $100 \mathrm{rpm}$ and using uncoated microcontainers loaded with LGG as control. The release profiles were monitored real time through in situ UV probes with a path length of $20 \mathrm{~mm}$.

\subsubsection{Ex-vivo release studies in rat GI contents}

Non-sterile cecal and intestinal contents were obtained from the cecum, proximal (pro) colon and distal (dis) colon of male Sprague-Dawley rats (Charles River Laboratories, Wilmington, MA, USA). The cecal and intestinal contents were diluted in ultrapure water to obtain the release media with dry content of $10 \mathrm{mg} / \mathrm{mL}^{56}$. The prepared media was added to vials containing the chips holding the microcontainers (loaded with LGG and coated with chitosan-genipin) and was kept under anaerobic conditions at $37^{\circ} \mathrm{C}$ with continuous shaking at $90 \mathrm{rpm}$. To examine the release and survival of LGG, $100 \mu \mathrm{L}$ samples were taken at 90, 180 and $270 \mathrm{~min}$. CFU of LGG for each sample was determined and standardized by the weight of the spray dried powder loaded into the microcontainers. All experiments were carried out in triplicates and the release of LGG from uncoated microcontainers in PBS was used as control.

\subsection{In vivo evaluation of colon-specific delivery of LGG}


Animal experiments were performed according to the Danish and European guidelines for animal housing and care and the euthanasia procedures followed the humane endpoints stated in welfare norms at the National Food Institute at the Technical University of Denmark. The experiments were carried out under the approval of the local institutional Animal Welfare Committee, license number 2015-15-0201-00553 and in compliance with Danish laws regulating experiments on animals and EC Directive 2010/ 63/EU.

Microcontainers were loaded with spray dried LGG and spray coated with EL-100 (sample 1) and chitosan-genipin (sample 2) (Figure 2-A). The coated microcontainers were detached from the chips and loaded in the gelatin capsules, each capsule containing $580 \pm 19$ microcontainers hence, $5.41 \pm 0.18 \mathrm{mg}$ of spray dried LGG.

Localization of the released LGG from microcontainers coated with chitosan-genipin in the GI tract and the visualization of the coated microcontainers in the intestines of rats were investigated during two in vivo experiments as described in the following (Figure 2-B,C).

\subsubsection{Localization of the delivered $L G G$ in the GI tract of rats}

14 male 8-week-old Sprague-Dawley rats (Charles River Laboratories, Wilmington, MA, USA) were housed in pairs and had access to water and standard feed ad libitum. The animals were weighed before the start of the experiment $(434 \pm 21.7 \mathrm{~g})$ and dosed with one capsule/animal by oral gavage. Group $1(\mathrm{n}=6)$ was dosed with sample 1 (EL-100 coated microcontainers), while the animals in group $2(\mathrm{n}=8)$ were dosed with sample 2 (chitosan-genipin coated microcontainers). Animals from both groups were sacrificed at 6 or $24 \mathrm{~h}(\mathrm{n}=3$ for group 1 and $\mathrm{n}=4$ for group 2$)$ after dosing and dissected (Figure 2-B). The intestinal and cecal contents were sampled from the ileum, cecum, pro and dis colon and serial diluted. The diluted samples were plated and incubated at $37^{\circ} \mathrm{C}$ 
for $48 \mathrm{~h}$ under anaerobic conditions, followed by CFU counting. The obtained CFU values were standardized by the weight of the spray dried powder loaded in the capsules.

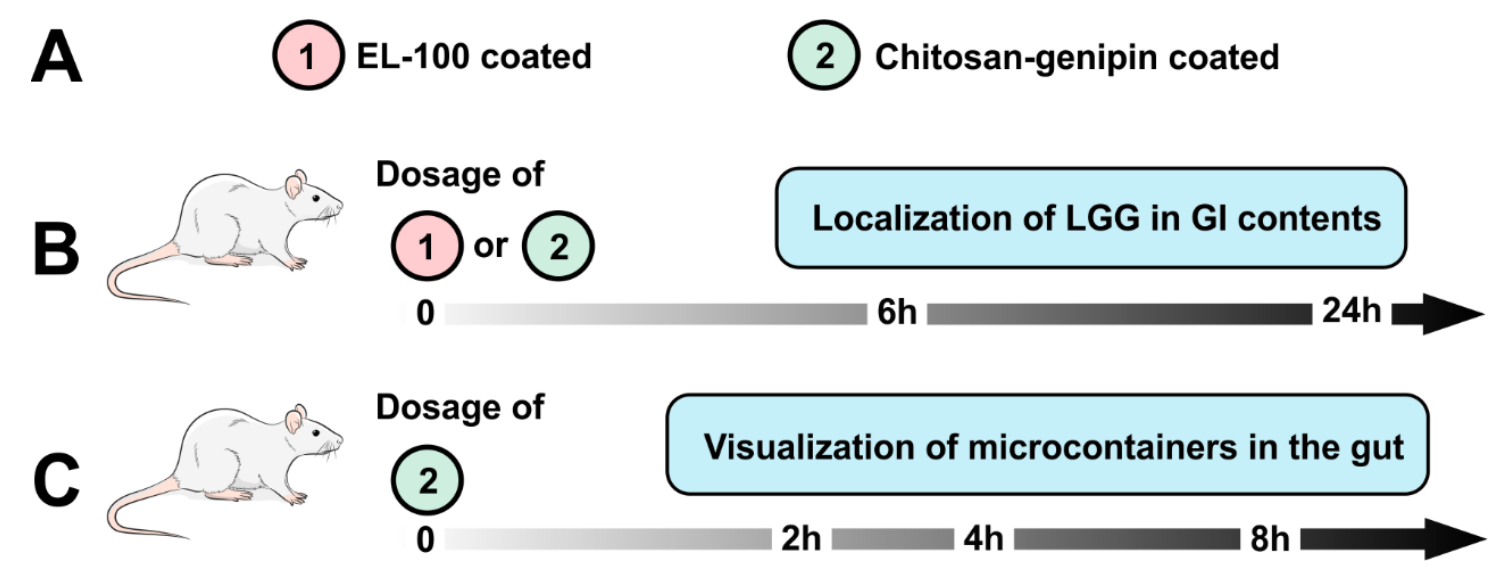

Figure 2. Schematic representation of the in vivo studies, showing (A) the two tested samples, namely EL-100 (sample 1) and chitosan-genipin (samples 2) coated microcontainers containing spray dried LGG, (B) the experimental plan for the evaluation of the location and quantity of LGG released from samples 1 and 2 at 0,6 and $24 \mathrm{~h}$ and (C) the strategy for the visualization of the GI tract of rats dosed with sample 2 at $0,2,4$ and $8 \mathrm{~h} .$. For both experiments, the rats were sacrificed and dissected at the defined time points during $24 \mathrm{~h}$.

\subsubsection{Visualization of microcontainers in the intestines of rats}

As indicated in Figure 2-C, the microcontainers were visualized in vivo using 6 male 8-weekold Sprague-Dawley rats, housed in pairs with access to water and standard feed and weighed before the start of the experiment $(366.4 \pm 18 \mathrm{~g})$. In order to visualize the chitosan-genipin coated microcontainers in the GI tract, animals were orally dosed with sample 2 and sacrificed at 2, 4 and $8 \mathrm{~h}$ after dosing ( $\mathrm{n}=2$ at each time point, Figure 2-C). At each time point, the rats were dissected and their GI tract from the duodenum to the dis colon was removed, sectioned into $5 \mathrm{~cm}$ fragment, placed on glass slides and opened using a scalpel. The visualization of the microcontainers in the 
intestines was performed using an optical microscope (U-RFL-T mercury/xenon burner with a ULH100HG microscope (Olympus ${ }^{\circledR}$, Tokyo, Japan) and CellSens Entry software (version 1.12, Olympus ${ }^{\circledR}$, Tokyo, Japan)).

\subsection{Data analysis}

All data is presented as mean \pm standard deviation (SD). Statistical analysis and plotting of data were conducted using OriginLab software (OriginLab Corporation, Northampton, MA, USA). $p$ values were calculated using an un-paired t-test ( $p \leq 0.05$ was considered significant).

\section{Results and Discussion}

\subsection{Characterization of genipin-crosslinked chitosan}

\subsubsection{Characterization of the crosslinking process}

Covalent crosslinking of chitosan with genipin was investigated using UV-visible spectroscopy (Figure 3). The complex mechanism of the crosslinking process consists of multiple reactions, leading to a green-blue coloration in the reaction mixture ${ }^{57}$. The progress of the crosslinking reaction was monitored in real time for $24 \mathrm{~h}$ as shown in Figure 3-A, which reveals a distinct change in the peaks at 210, 280, 360 and $600 \mathrm{~nm}$ during the measurement. Figure 3-B shows the increase in the absorbance of the reaction mixture at $600 \mathrm{~nm}$, corresponding to the formation of blue pigment coloration of the chitosan-genipin mixture over time. The coloration of the chitosan and genipin mixture can be observed in the inset of Figure 3-B. 

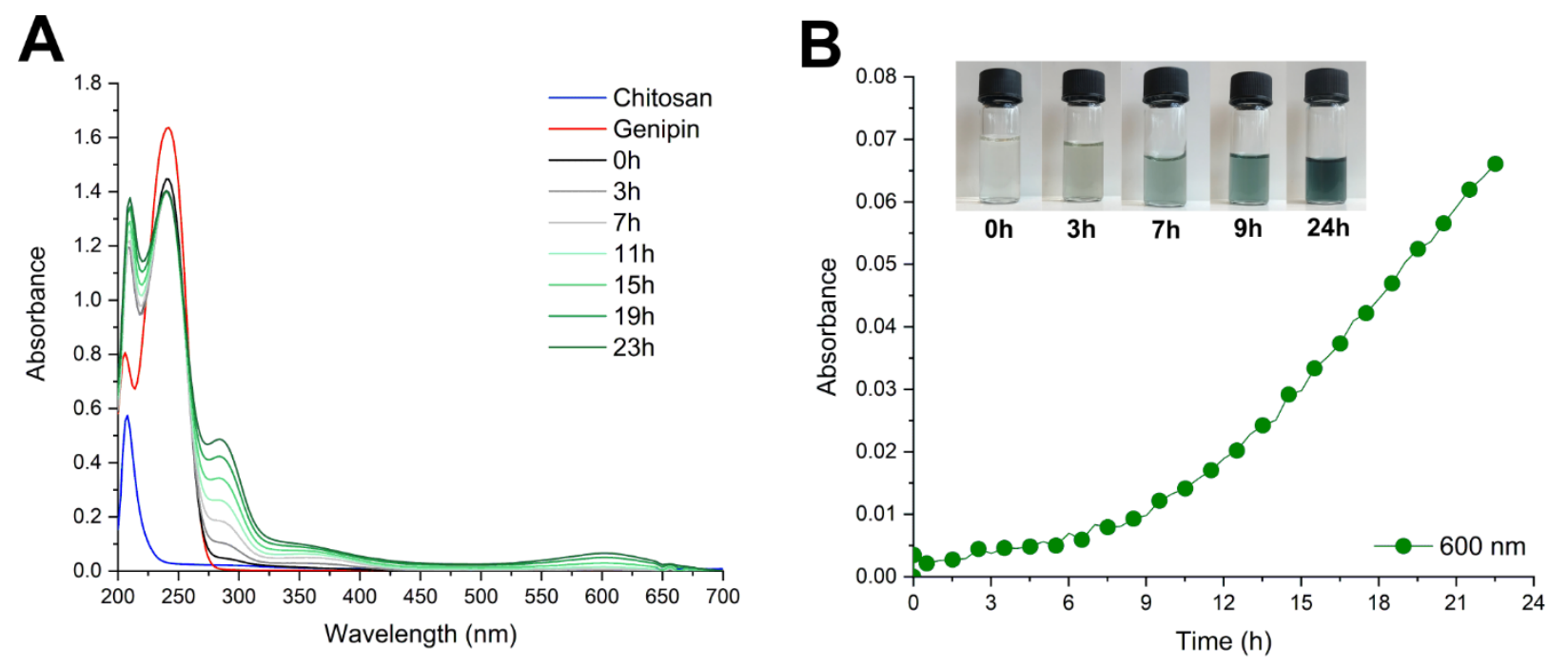

Figure 3. (A) UV-visible spectra of chitosan and genipin and genipin-crosslinked chitosan over time. (B) Increase in the absorbance of chitosan-genipin mixture at $600 \mathrm{~nm}$, over $24 \mathrm{~h}$ (correlating to the spectra presented in (A)). (B-inset) coloration of the chitosan-genipin reaction mixture over time.

\subsection{2. pH-stability and swelling}

pH-responsiveness of genipin-crosslinked chitosan was investigated using QCM-D. For this purpose, a silica sensor was coated with a thin layer of chitosan-genipin (Figure 4-A) and exposed to $\mathrm{pH}$ of 2.5 and 7.5 to monitor frequency and dissipation shifts over time (Figure 4-B). It can be observed that a small shift occurs in frequency and dissipation of the $3^{\text {rd }}$ overtone $(\Delta \mathrm{f}=6 \mathrm{~Hz}, \Delta \mathrm{D}=-$ 2E-6), when changing the medium from $\mathrm{pH}=2.5$ to $\mathrm{pH}=7.4$ and the same shift can be seen when changing back to $\mathrm{pH}=2.5$. A similar trend is visible for the $5^{\text {th }}$ and $7^{\text {th }}$ overtones. This trend is explained by the slightly swollen film at $\mathrm{pH}=2.5$ due to the highly charged status of chitosan at this $\mathrm{pH}\left(\mathrm{pK}_{\mathrm{a}}=6-6.5^{58}\right)$, and a decrease in the amount of swelling after changing to $\mathrm{pH}=7.4$ due to the semi-charged nature of chitosan in neutral $\mathrm{pH}^{59}$. These results also suggest that covalent crosslinking of chitosan can lead to a higher $\mathrm{pH}$-stability, compared to the conventional approach of using the electrostatic interactions in a polyelectrolyte complex ${ }^{60,61}$. 

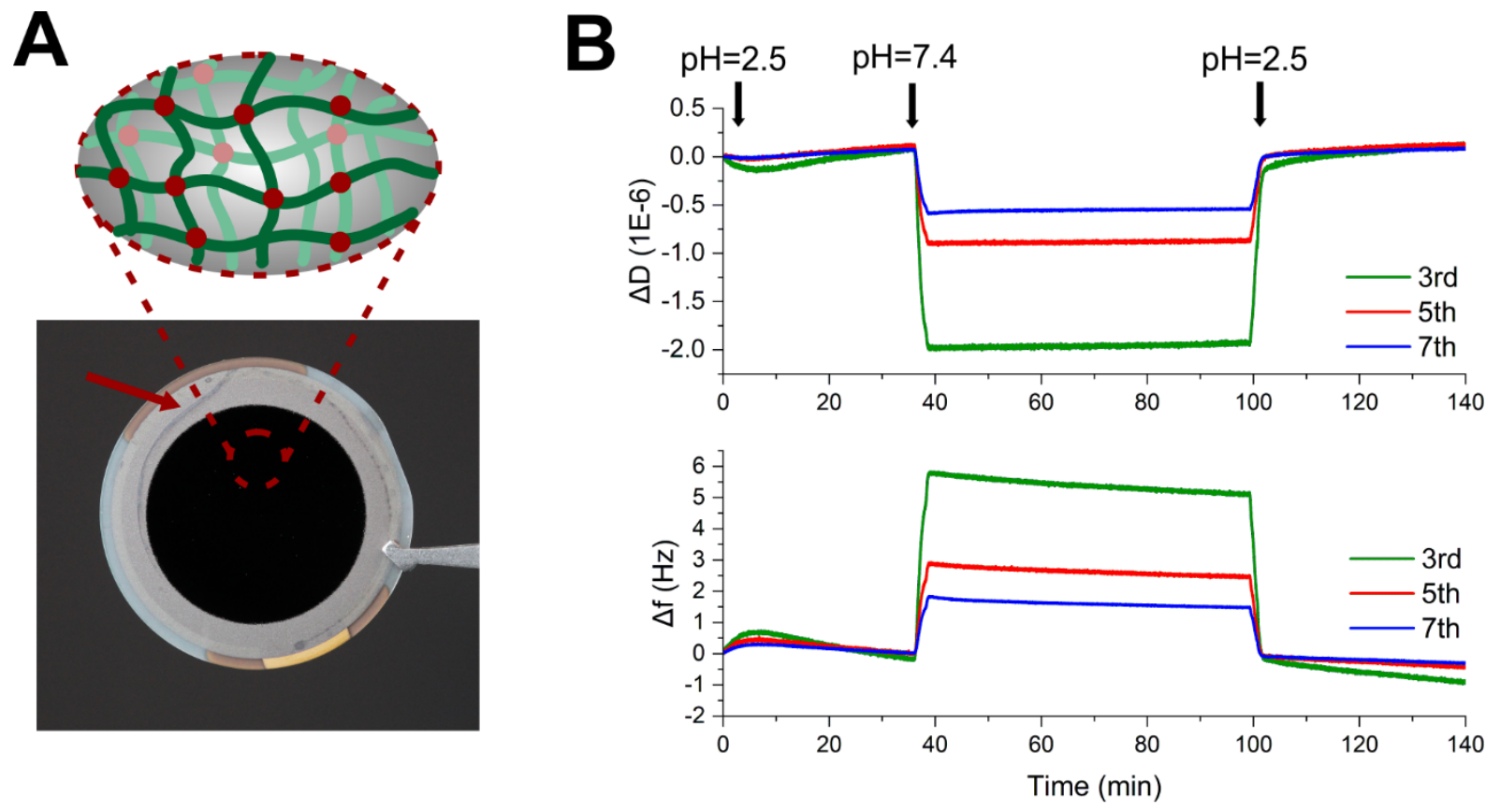

Figure 4. QCM-D analysis of genepin-crosslinked chitosan, showing (A) chitosan-genipin coated sensor and (B) $\mathrm{pH}$ responsiveness of the deposited layer. A-inset schematically illustrates the genipin-crosslinked chitosan and arrow points to the edge of the coated layer on the sensor.

\subsection{LGG-loaded microcontainers coated with chitosan-genipin}

Figure 5-A shows the viability of LGG before and after the spray drying process, which reveals a survival rate of $118.87 \pm 29.59 \%$. Figure 5-(B-E) represents empty microcontainers loaded with spray dried LGG and coated with chitosan-genipin. It is evident from the SEM images that the coating successfully seals the reservoir of the microcontainers (elaborated further in supporting information S2). 

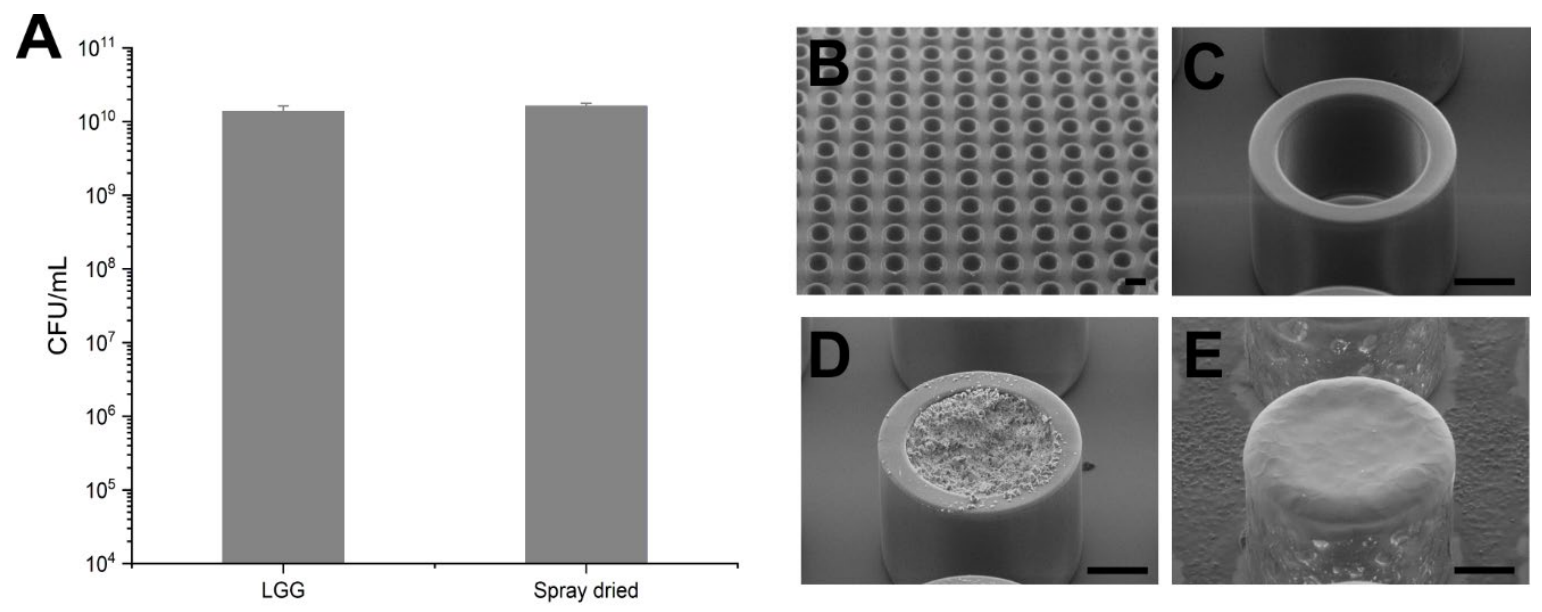

Figure 5. (A) Bacterial count of LGG before and after spray drying. SEM images of (B) a chip containing empty microcontainers, (C) single microcontainer, (D) loaded with spray dried LGG and (E) coated with chitosan-genipin. scale bar $=200 \mu \mathrm{m}$. Data is presented as mean $(n=3) \pm S D$.

To test the potential of chitosan-genipin as a coating for colon targeted delivery of probiotics, the release of LGG from the coated microcontainers was investigated. Figure 6-A,B shows the cumulative release profiles from uncoated and coated (chitosan and chitosan-genipin) microcontainers in media with $\mathrm{pH}=2.5$ and $\mathrm{pH}=7.4$. A cumulative release of $103.9 \pm 2.1 \%$ in $\mathrm{pH}=2.5$ and $88.8 \pm 6.5 \%$ in $\mathrm{pH}=7.4$ was observed from chitosan coated microcontainers, similar to the release recorded from uncoated ones ( $p=0.234$ and $p=0.103$, respectively). As hypothesized earlier, the rapid release from the chitosan-coated microcontainers at $\mathrm{pH}=2.5$ (Figure 6-A) can be explained by the highly charged polymeric chains at this $\mathrm{pH}^{42}$. On the other hand, the slower release from this coating at $\mathrm{pH}=7.4$ (Figure 6-B) can be attributed to hydration and partial swelling of chitosan. This observation is in accordance with previous studies on the release of drugs from chitosan matrixes ${ }^{62}$ and matches with previous reports on chitosan-coated microcontainers ${ }^{24,25}$. 

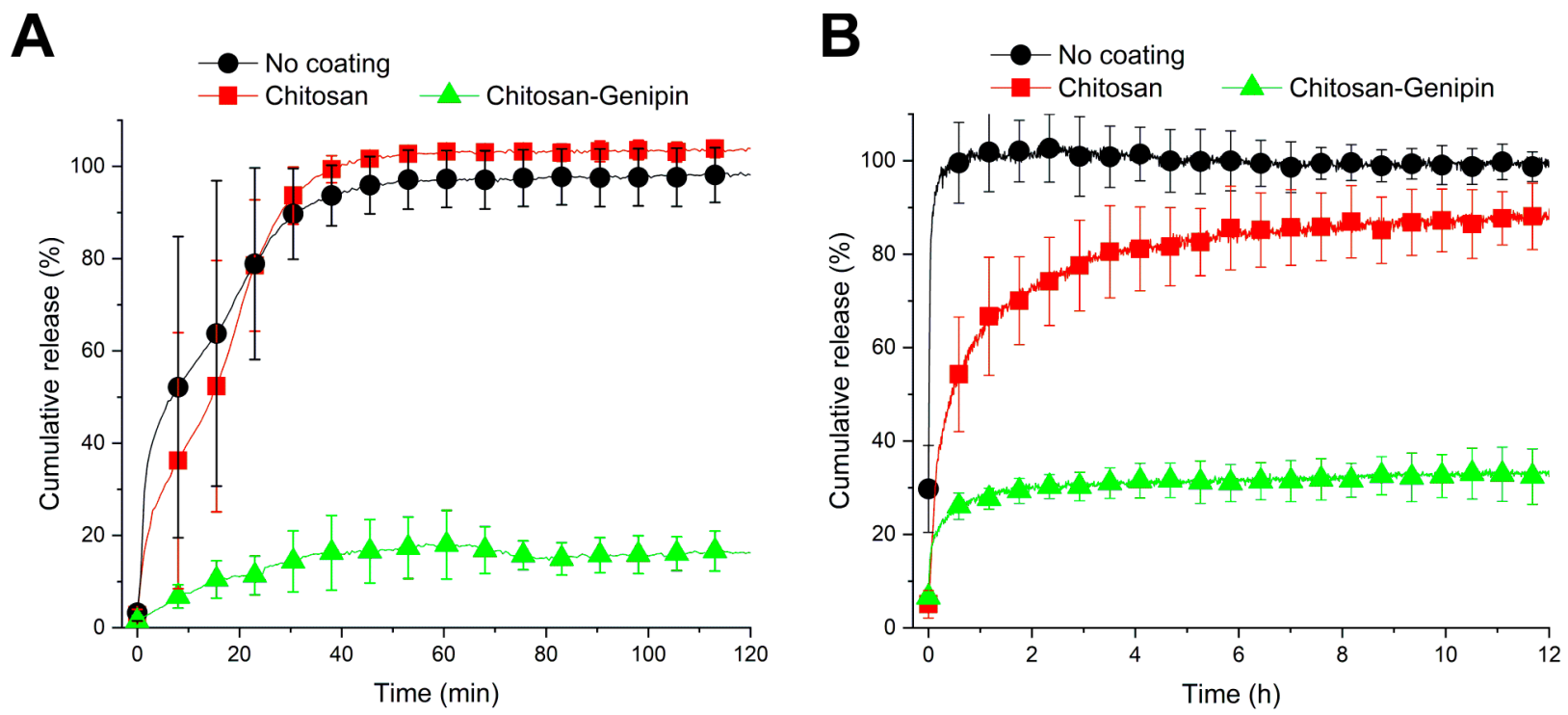

Figure 6. Cumulative release of spray dried LGG from microcontainers with no coating, coated with chitosan and chitosan-genipin in media with (A) $\mathrm{pH}=2.5$ and (B) $\mathrm{pH}=7.4$. Data is presented as mean $(\mathrm{n}=3) \pm \mathrm{SD}$.

The release profiles from microcontainers coated with chitosan-genipin in gastric $\mathrm{pH}$ (Figure 6A) indicates that only a small amount of LGG was released (16.2 $\pm 4.4 \%)$ over a period of $2 \mathrm{~h}$. On the other hand, the cumulative release is slightly higher $(32.4 \pm 6.0 \%)$ at intestinal $\mathrm{pH}$ (Figure 6-B) during $12 \mathrm{~h}$. The higher release at $\mathrm{pH}=7.4$ compared to that of $\mathrm{pH}=2.5$ can be explained by the faster dissolution of the spray dried LGG at this $\mathrm{pH}$, through comparison of the cumulative release of the powder from uncoated microcontainers at $\mathrm{pH}=2.5$ (55.4 \pm 33.0 after $10 \mathrm{~min})$ compared to that of $\mathrm{pH}=7.4(93.4 \pm 12.4$ after $10 \mathrm{~min})$. These results show a statistically significant difference between the capabilities of chitosan and chitosan-genipin coatings to sustain the release of LGG in $\mathrm{pH}=2.5$ and $7.5\left(p=2.32 \times 10^{-4}\right.$ and $8.1 \times 10^{-3}$, respectively). These findings are in accordance with previous studies showing controlled release of encapsulated drugs by genipin-crosslinking of chitosan microspheres ${ }^{63}$. As the potential of the chitosan-genipin coating for colon-specific delivery of LGG was established, the coating was further investigated in in vitro and ex vivo assays. 


\subsection{In vitro and ex vivo evaluation of chitosan-genipin coated microcontainers}

\subsubsection{Release of LGG in simulated GI conditions}

The release of LGG from chitosan-genipin coated microcontainers was further tested in media simulating the sequential $\mathrm{pH}$ variations and transit times of the GI tract and the presence of colonic enzymes of rats ${ }^{51,53}$. Figure 7 -A shows the cumulative release form chitosan-genipin coated microcontainers with uncoated microcontainers as a control, in the simulated phases of stomach, small intestine and colon. It can be observed that in accordance with the previous results (Figure 6-A,B), there was a $9.7 \pm 1.8 \%$ release in the gastric phase $(\mathrm{pH}=2.5)$, followed by a release of up to $37.3 \pm 6.7 \%$ in the small intestinal phase $(\mathrm{pH}=7.4)$.
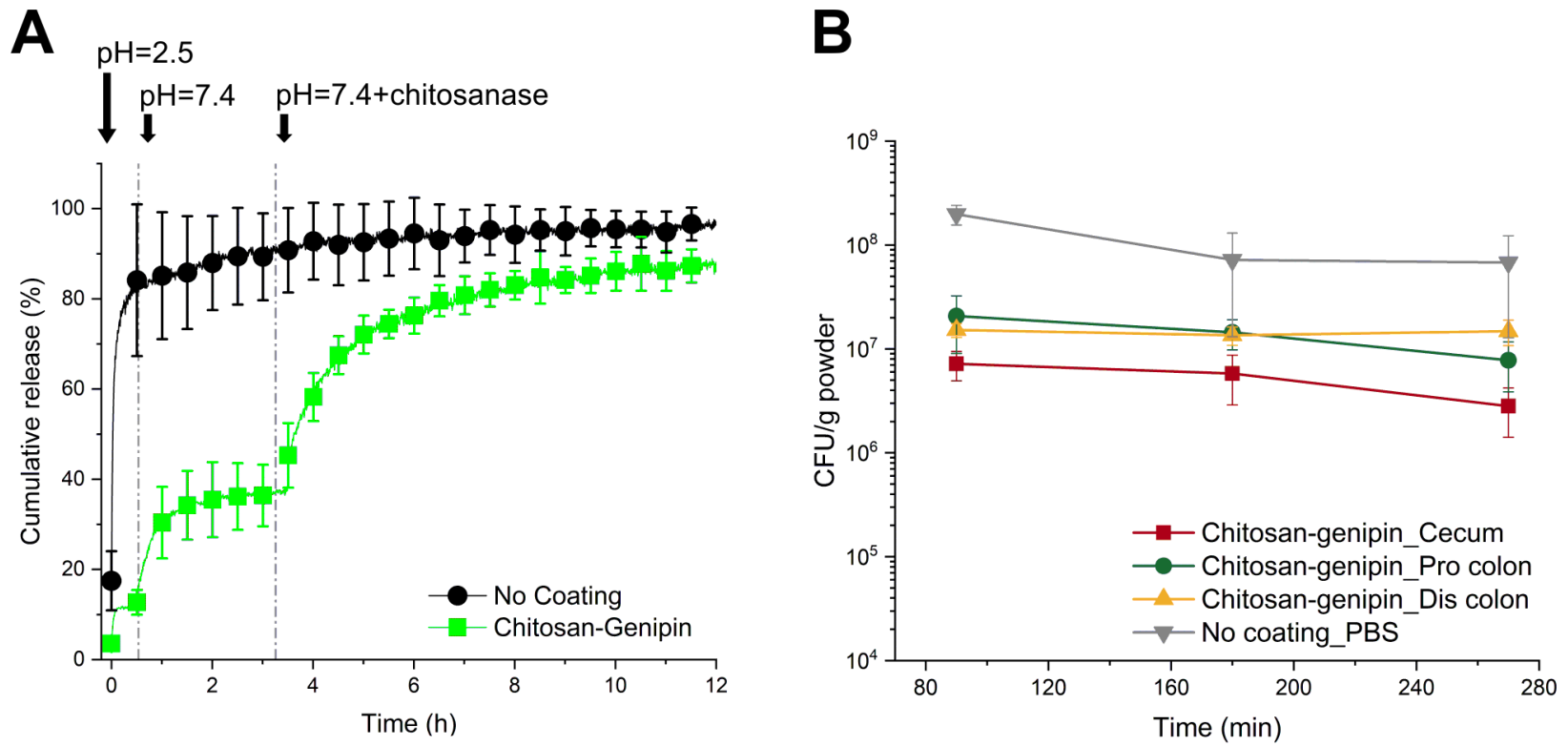

Figure 7. (A) Cumulative release profiles from microcontainers loaded with LGG with no coating and coated with chitosan-genipin in simulated GI conditions of rats. (B) Bacterial counts of LGG released from chitosan-genipin coated microcontainers in contents isolated from cecum, pro colon and dis colon of rats with uncoated microcontainers in PBS as control. Data is presented as mean $(n=3) \pm$ SD. 
This premature release, which was also observed in Figure 6-B, can be explained by the infusion of the spray dried powder with the coating during the lid deposition process and subsequent release through partial swelling of the lid. Such observations have also been reported in previous studies on enteric coated microcontainers ${ }^{20,64}$. In the final step, in the presence of chitosanase enzymes, there was a gradual release of up to $91.6 \pm 5.6 \%$. Based on these findings, it can be concluded that the chitosan-genipin coating is degraded slowly by the enzymes, which resulted in a release of $78.16 \pm 3.6 \%$ after $2 \mathrm{~h}$.

These results were confirmed by microscopy images of the coated microcontainers after the full release of LGG (Figure S3). Although, these results confirm the enzyme-sensitive mechanism of release through degradation of the coating, they do not provide sufficient information on the performance of the delivery system under in vivo conditions ${ }^{30}$. Therefore, the performance of the coating was investigated in an ex vivo assay in the cecal and intestinal contents of rats.

\subsubsection{Release of $L G G$ in rat GI contents}

Figure 7-B shows CFU of LGG released from the chitosan-genipin coated microcontainers after 90, 180 and $270 \mathrm{~min}$ in rat cecal and intestinal contents. We could observe that LGG was released after 90 min in the cecum, pro colon and dis colon, which is in accordance with previous reports on biodegradation of chitosan in the GI contents of rats ${ }^{65,66}$. The release mechanism was also investigated by SEM imaging, which suggested a similar trend in the disintegration of the coating in the rat GI contents and in the presence of chitosanase (supporting information S3). These observations indicate an enzyme-triggered release, and furthermore confirm that LGG is detectable among other bacteria present in the contents of the lower GI tract of rats. Therefore, these findings were proceeded by in vivo studies in rats.

\subsection{In vivo examination of chitosan-genipin coated microcontainers}




\subsubsection{Localization of $L G G$ in the GI tract of rats}

Figure 8-A,B presents chitosan-genipin coated microcontainers loaded with LGG after detachment from the carrier chip and loaded into a gelatin capsule. SEM and optical microscopy images of the detached microcontainers (Figure 8-A, B-inset) show that the coating was intact and undamaged after detachment from the chips. Figure 8-C,D shows CFU counts of LGG in samples collected from the GI tract of rats at 6 and $24 \mathrm{~h}$ after dosing. Based on the measured CFU counts, and the assumption that LGG does not proliferate rapidly in the crowded colonic environment, we assume that the enumerated LGG are 'primary' released bacterial cells, and not bacteria proliferated after release. We observed (Figure 8-C,D) that there were no detectable LGG in the ileum of the animals dosed with the chitosan-genipin coated microcontainers at 6 or $24 \mathrm{~h}$; however LGG was present in the cecum and pro colon after $6 \mathrm{~h}$ and reached the dis colon at $24 \mathrm{~h}$. Therefore, these results confirm that LGG is contained inside the chitosan-genipin coated microcontainers while passing through the ileum.

In the case of EL-100-coated microcontainers (Figure 8-C,D), LGG was present in the small intestine at 6 and 24. These findings are in accordance with previous studies on EL-100 coated microcontainers, which showed the release of a loaded compound in the beginning of the small intestine $^{20,51,64}$. Based on these observations, we infer that it is indeed the chitosan-genipin coating which facilitates the protection of LGG in the upper GI tract. 


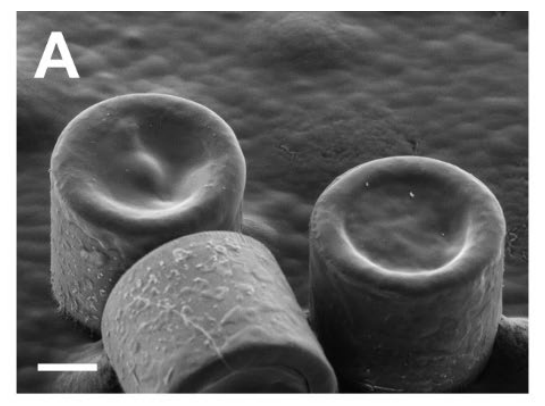

C

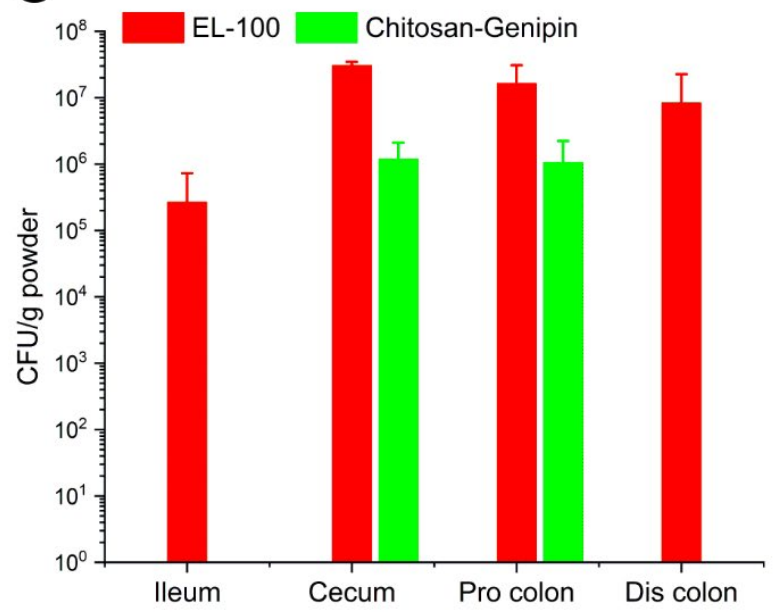

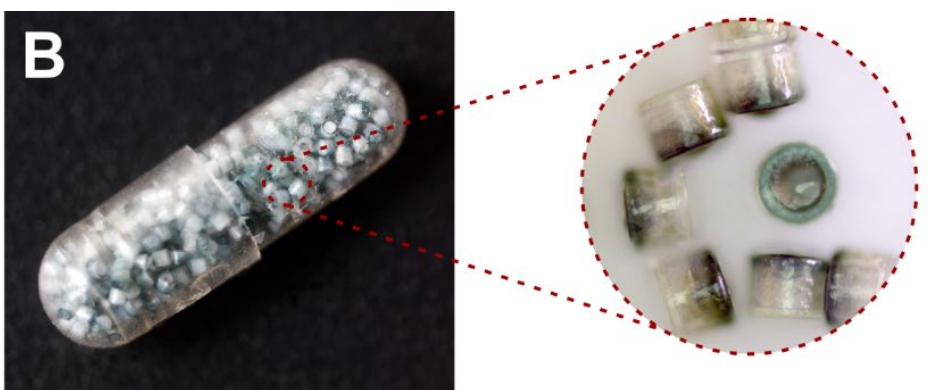

D

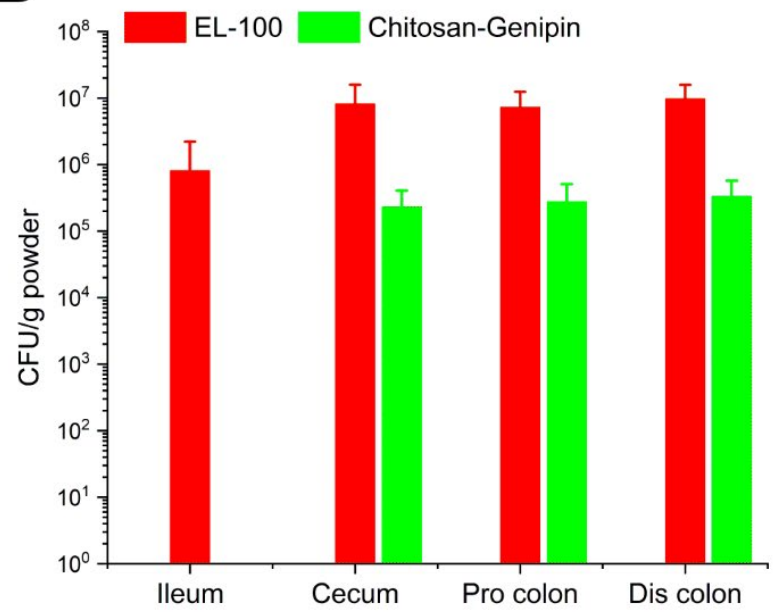

Figure 8. (A) SEM image of chitosan-genipin coated microcontainers after detachment from the chip and (B) photo of coated microcontainers loaded into a rat size gelatin capsule. (B)-inset shows Optical microscopy image of chitosan-genipin coated microcontainers. CFU of detected LGG released from microcontainers coated with chitosan-genipin $(n=4)$ and microcontainers coated with EL-100 ( $\mathrm{n}=3)$ in the ileum, cecum, pro colon and dis colon of rats, (C) $6 \mathrm{~h}$ and (D) $24 \mathrm{~h}$ after dosage. Scale bar $=100 \mu \mathrm{m}$. Data is presented as mean $\pm \mathrm{SD}$. Detection limit $=10^{3} \mathrm{CFU} / \mathrm{g}$.

The presented results show a decrease in bacterial cell viability in the samples coated with chitosan-genipin compared to those coated with EL-100, suggesting that the sample preparation steps i.e. spray coating temperature and humidity during crosslinking may need to be further optimized. 
The findings in Figure 8-C additionally suggest that the chitosan-genipin coated microcontainers had traveled slower through the gut compared to the EL-100-coated, as LGG from the chitosan-genipin samples was not detectable in the distal colon after $6 \mathrm{~h}$. This observation could be related to the stronger adhesion of the chitosan-genipin coated microcontainers to the intestinal mucus layer as a result of the mucoadhesive properties of chitosan ${ }^{67,68}$. Overall, our findings confirm that the developed carrier system can deliver the probiotics locally in the colon without any premature release in the small intestine.

\subsubsection{Visualization of microcontainers in the intestines}

Figure 9 shows microscopy images of individual microcontainers located in the distinct segments of the GI tract at different time points (Elaborated further in supporting information S4). $2 \mathrm{~h}$ after dosing, microcontainers were found mainly in the jejunum and few were located in the ileum, where the microcontainers were found sealed and the chitosan-genipin lids were intact. After $4 \mathrm{~h}$, the delivery devices were found mostly in the distal part of the ileum and some were located in the cecum and the pro colon. We could observe that the microcontainers found in the small intestine were still sealed. However, those located in the cecum and the pro colon, were found open and the lids had degraded. After $8 \mathrm{~h}$, the microcontainers were located in the middle and the distal part of the colon, where the chitosan-genipin coatings had degraded, as can be seen in Figure 9. Our findings further confirm the ability of the developed coating to control the release of probiotics through an enzyme-sensitive mechanism and deliver LGG locally to the colon. 
$2 \mathrm{~h}$
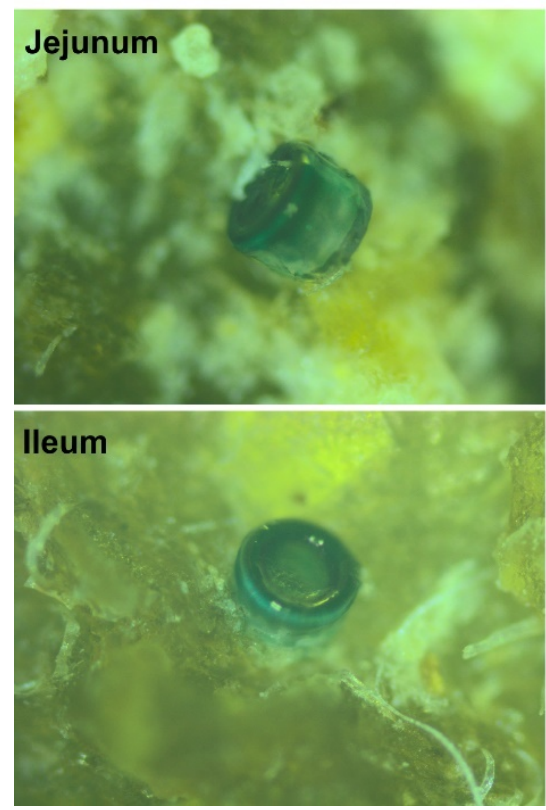

4h
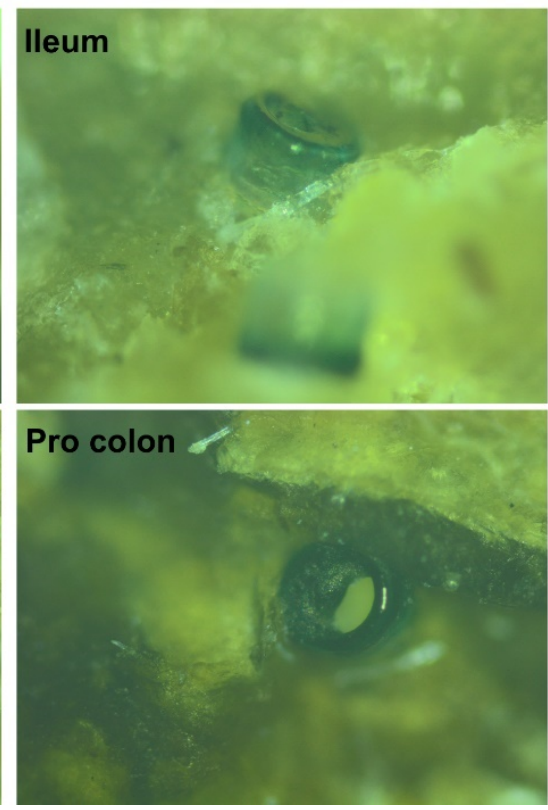

$8 \mathrm{~h}$
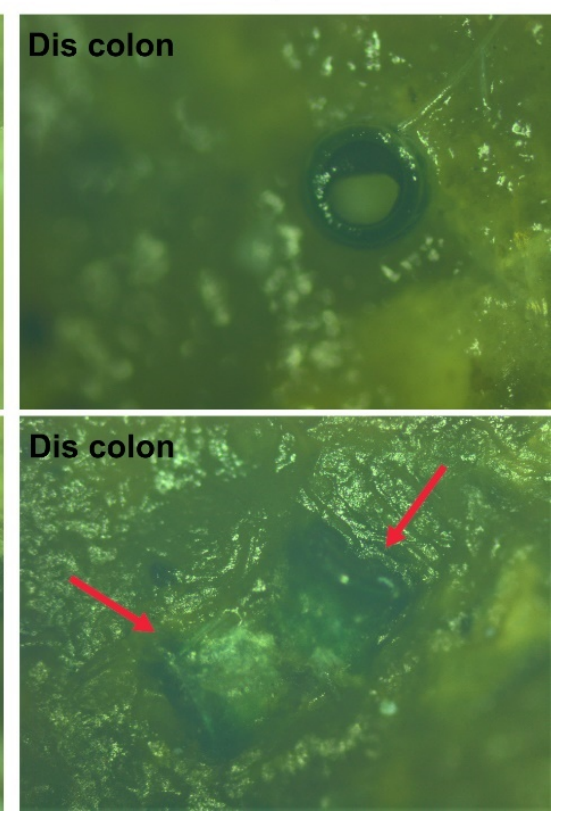

Figure 9. Visualization by optical microscopy of chitosan-genipin coated microcontainers loaded with LGG in the GI tract of rats at, 2, 4 and $8 \mathrm{~h}$ after oral dosage. Arrows point at the microcontainers embedded in the colonic contents.

\section{Conclusions}

In this study, we have developed an enzymatically triggered delivery system based on microcontainers sealed with crosslinked chitosan coatings for the widely used bacterial strain, Lactobacillus rhamnosus GG, as a model microorganism in order to provide proof-of-concept for colon-specific delivery of bioactive agents. Chitosan was covalently crosslinked using genipin as a strong, yet nontoxic and biocompatible crosslinker, to design a coating that is stable at gastric and intestinal $\mathrm{pH}$ with controllable swelling.

The results of in vitro, ex vivo and in vivo studies confirm that the coated microcontainers can delay the release of the loaded microorganisms throughout the $\mathrm{pH}$ variations of the upper GI tract and deliver the probiotics locally in the cecum and colon of rats. Based on the presented results, 
the modification of chitosan through chemical crosslinking as a coating for orally ingestible microdevices, shows great promise for colon-targeted delivery of bioactive agents. The obtained results of this study shall be investigated further to understand the effect of colon-specific delivery on the growth and colonization of probiotic microorganisms delivered locally by chitosan-genipin coated microcontainers.

\section{Supporting Information}

UV-vis spectra of skim milk and spray dried LGG; Optical microscopy and SEM images of microcontainers before, during and after the loading and coating processes; SEM images of chitosan-genipin coated microcontainers after release of LGG; Additional optical microscopy images of chitosan-genipin coated microcontainers inside the GI tract of rats.

Corresponding author: Khorshid Kamguyan; khokam@,dtu.dk

\section{Notes}

The authors declare no conflicts interests.

\section{Acknowledgements}

This study was supported by the Novo Nordisk Foundation (NNF17OC0026910) as a part of the project MIMIO -Microstructures, microbiota and oral delivery-and the Danish National Research Foundation (DNRF122) and the Villum Foundation (Grant No. 9301) as a part of the Center for Intelligent Drug Delivery and Sensing Using Microcontainers and Nanomechanics (IDUN). 
The authors would like to thank Lasse Højlund Eklund Thamdrup and Jesper Scheel from the Department of Health Technology, Technical University of Denmark for the fabrication of the microcontainers and photography, respectively. The authors also thank Katja Ann Kristensen and Pi Westi Bondegaard from the National Food Institute, Technical University of Denmark for their help during the different stages of the project.

\section{References}

(1) Gorbach, S. L. INTESTINAL MICROFLORA. Gastroenterology 1971, 60 (6), 1110-1129. https://doi.org/10.1016/S0016-5085(71)80039-2.

(2) Fuller, R. Probiotics in Man and Animals. J. Appl. Bacteriol. 1989, 66, 365-378.

(3) Macfarlane, G. T.; Cummings, J. H. Probiotics and Prebiotics: Can Regulating the Activities of Intestinal Bacteria Benefit Health? West. J. Med. 1999, 171 (3), 187-191. https://doi.org/10.1136/bmj.318.7189.999.

(4) Sartor, R. Genetics and Environmental Interactions Shape the Intestinal Microbiome to Promote Inflammatory Bowel Disease Versus Mucosal Homeostasis. Gastroenterology 2010, 139, 1816-1819. https://doi.org/10.1053/j.gastro.2010.10.036.

(5) Govender, M.; Choonara, Y. E.; Kumar, P.; du Toit, L. C.; van Vuuren, S.; Pillay, V. A Review of the Advancements in Probiotic Delivery: Conventional vs. Non-Conventional Formulations for Intestinal Flora Supplementation. AAPS PharmSciTech 2014, 15 (1), 2943. https://doi.org/10.1208/s12249-013-0027-1.

(6) Gbassi, G. K.; Vandamme, T. Probiotic Encapsulation Technology: From Microencapsulation to Release into the Gut. Pharmaceutics 2012, 4 (1), 149-163. https://doi.org/10.3390/pharmaceutics4010149. 
(7) Aggarwal, N.; Breedon, A. M. E.; Davis, C. M.; Hwang, I. Y.; Chang, M. W. Engineering Probiotics for Therapeutic Applications: Recent Examples and Translational Outlook. Curr. Opin. Biotechnol. 2020, 65, 171-179. https://doi.org/10.1016/j.copbio.2020.02.016.

(8) Fadhlaoui, K.; Arnal, M. E.; Martineau, M.; Camponova, P.; Ollivier, B.; O’Toole, P. W.; Brugère, J. F. Archaea, Specific Genetic Traits, and Development of Improved Bacterial Live Biotherapeutic Products: Another Face of next-Generation Probiotics. Appl. Microbiol. Biotechnol. 2020, 104 (11), 4705-4716. https://doi.org/10.1007/s00253-02010599-8.

(9) Ropot, A. V.; Karamzin, A. M.; Sergeyev, O. V. Cultivation of the Next-Generation Probiotic Akkermansia Muciniphila, Methods of Its Safe Delivery to the Intestine, and Factors Contributing to Its Growth In Vivo. Current Microbiology. Springer August 1, 2020, pp 1363-1372. https://doi.org/10.1007/s00284-020-01992-7.

(10) Sun, F.; Zhang, Q.; Zhao, J.; Zhang, H.; Zhai, Q.; Chen, W. A Potential Species of NextGeneration Probiotics? The Dark and Light Sides of Bacteroides Fragilis in Health. Food Research International. Elsevier Ltd December 1, 2019, p 108590. https://doi.org/10.1016/j.foodres.2019.108590.

(11) Nielsen, L. H.; Keller, S. S.; Boisen, A. Microfabricated Devices for Oral Drug Delivery. Lab Chip 2018, 18 (16), 2348-2358. https://doi.org/10.1039/c8lc00408k.

(12) Tao, S. L.; Desai, T. A. Microfabricated Drug Delivery Systems: From Particles to Pores. Advanced Drug Delivery Reviews. Elsevier February 24, 2003, pp 315-328. https://doi.org/10.1016/S0169-409X(02)00227-2.

(13) Mandsberg, N. K.; Christfort, J. F.; Kamguyan, K.; Boisen, A.; Srivastava, S. K. Orally Ingestible Medical Devices for Gut Engineering. Adv. Drug Deliv. Rev. 2020. 
https://doi.org/10.1016/j.addr.2020.05.004.

(14) Asgari, S.; Pourjavadi, A.; Licht, T. R.; Boisen, A.; Ajalloueian, F. Polymeric Carriers for Enhanced Delivery of Probiotics. Advanced Drug Delivery Reviews. Elsevier B.V. July 21, 2020. https://doi.org/10.1016/j.addr.2020.07.014.

(15) Ahmed, A.; Bonner, C.; Desai, T. A. Bioadhesive Microdevices with Multiple Reservoirs: A New Platform for Oral Drug Delivery. J. Control. Release 2002, 81 (3), 291-306. https://doi.org/10.1016/S0168-3659(02)00074-3.

(16) Ainslie, K. M.; Lowe, R. D.; Beaudette, T. T.; Petty, L.; Bachelder, E. M.; Desai, T. A. Microfabricated Devices for Enhanced Bioadhesive Drug Delivery: Attachment to and Small-Molecule Release through a Cell Monolayer under Flow. Small 2009, 5 (24), 28572863. https://doi.org/10.1002/smll.200901254.

(17) von Halling Laier, C.; Gibson, B.; Moreno, J. A. S.; Rades, T.; Hook, S.; Nielsen, L. H.; Boisen, A. Microcontainers for Protection of Oral Vaccines, in Vitro and in Vivo Evaluation. J. Control. Release 2019, 294, 91-101. https://doi.org/10.1016/J.JCONREL.2018.11.030.

(18) Nielsen, L. H.; Keller, S. S.; Gordon, K. C.; Boisen, A.; Rades, T.; Müllertz, A. Spatial Confinement Can Lead to Increased Stability of Amorphous Indomethacin. Eur. J. Pharm. Biopharm. 2012, 81 (2), 418-425. https://doi.org/10.1016/j.ejpb.2012.03.017.

(19) Nielsen, L. H.; Melero, A.; Keller, S. S.; Jacobsen, J.; Garrigues, T.; Rades, T.; Müllertz, A.; Boisen, A. Polymeric Microcontainers Improve Oral Bioavailability of Furosemide. Int. J. Pharm. 2016, 504 (1-2), 98-109. https://doi.org/10.1016/J.IJPHARM.2016.03.050.

(20) Mazzoni, C.; Tentor, F.; Strindberg, S. A.; Nielsen, L. H.; Keller, S. S.; Alstrøm, T. S.; Gundlach, C.; Müllertz, A.; Marizza, P.; Boisen, A. From Concept to in Vivo Testing: 
Microcontainers for Oral Drug Delivery. J. Control. Release 2017, 268, 343-351. https://doi.org/10.1016/J.JCONREL.2017.10.013.

(21) Vaut, L.; Juszczyk, J.; Kamguyan, K.; Jensen, K.; Tosello, G.; Boisen, A. 3D Printing of Reservoir Devices for Oral Drug Delivery and Enhanced Mucoadhesion. ACS Biomater Sci Eng 2020, 6, 2478-2486. https://doi.org/https://doi.org/10.1021/acsbiomaterials.9b01760.

(22) Christfort, J. F.; Guillot, A. J.; Melero, A.; Thamdrup, L. H. E.; Garrigues, T. M.; Boisen, A.; Zór, K.; Nielsen, L. H. Cubic Microcontainers Improve in Situ Colonic Mucoadhesion and Absorption of Amoxicillin in Rats. Pharmaceutics 2020, 12 (4), 355. https://doi.org/10.3390/pharmaceutics12040355.

(23) Nielsen, L. H.; Nagstrup, J.; Gordon, S.; Keller, S. S.; Østergaard, J.; Rades, T.; Müllertz, A.; Boisen, A. PH-Triggered Drug Release from Biodegradable Microwells for Oral Drug Delivery. Biomed. Microdevices 2015, 17 (3), 55. https://doi.org/10.1007/s10544-0159958-5.

(24) Mazzoni, C.; Jacobsen, R. D.; Mortensen, J.; Jørgensen, J. R.; Vaut, L.; Jacobsen, J.; Gundlach, C.; Müllertz, A.; Nielsen, L. H.; Boisen, A. Polymeric Lids for Microcontainers for Oral Protein Delivery. Macromol. Biosci. 2019, 19 (5), 1900004. https://doi.org/10.1002/mabi.201900004.

(25) Birk, S. E.; Haagensen, J. A. J.; Johansen, H. K.; Molin, S.; Nielsen, L. H.; Boisen, A. Microcontainer Delivery of Antibiotic Improves Treatment of Pseudomonas Aeruginosa Biofilms. Adv. Healthc. Mater. 2020, 1901779. https://doi.org/10.1002/adhm.201901779.

(26) Bak, A.; Ashford, M.; Brayden, D. J. Local Delivery of Macromolecules to Treat Diseases Associated with the Colon. Adv. Drug Deliv. Rev. 2018, 136-137, 2-27. https://doi.org/10.1016/j.addr.2018.10.009. 
(27) Koziolek, M.; Grimm, M.; Becker, D.; Iordanov, V.; Zou, H.; Shimizu, J.; Wanke, C.; Garbacz, G.; Weitschies, W. Investigation of PH and Temperature Profiles in the GI Tract of Fasted Human Subjects Using the Intellicap R System. J Pharm Sci 2015, 104, 28552863. https://doi.org/10.1002/jps.24274.

(28) Schiller, C.; Frohilch, C.-P.; Giessmann, T.; Siegmund, W.; Monnikes, H.; Hosten, N.; Weitschies, W. Intestinal Fluid Volumes and Transit of Dosage Forms as Assessed by Magnetic Resonance Imaging. Aliment. Pharmacol. Ther. 2005, 22 (10), 971-979. https://doi.org/10.1111/j.1365-2036.2005.02683.x.

(29) Englyst, H. N.; Hay, S.; Macfarlane, G. T. Polysaccharide Breakdown by Mixed Populations of Human Faecal Bacteria. FEMS Microbiol. Lett. 1987, 45 (3), 163-171. https://doi.org/10.1111/j.1574-6968.1987.tb02352.x.

(30) Yang, L.; Chu, J. S.; Fix, J. A. Colon-Specific Drug Delivery: New Approaches and in Vitro/in Vivo Evaluation. Int. J. Pharm. 2002, 235, 1-15. https://doi.org/https://doi.org/10.1016/S0378-5173(02)00004-2.

(31) Fallingborg, J.; Christensen, A.; Jacobsen, A.; Rasmussen, S. N. Very Low Intraluminal Colonic PH in Patients with Active Ulcerative Colitis. Dig. Dis. Sci. 1993, 38 (I1), 19891993. https://doi.org/10.1007/bf01297074.

(32) Salyers, A. A. Energy Sources of Major Intestinal Fermentative Anaerobes. American Journal of Clinical Nutrition. 1979, pp 158-163. https://doi.org/10.1093/ajcn/32.1.158.

(33) Hovgaard, L.; Brøndsted, H. Current Applications of Polysaccharides in Colon Targeting. Crit. Rev. Ther. Drug Carrier Syst. 1996, 13 (3-4), 185-223. https://doi.org/10.1615/CritRevTherDrugCarrierSyst.v13.i3-4.10.

(34) Vandamme, T. The Use of Polysaccharides to Target Drugs to the Colon. Carbohydr. 
Polym. 2002, 48 (3), 219-231. https://doi.org/10.1016/S0144-8617(01)00263-6.

(35) Chávarri, M.; Marañón, I.; Ares, R.; Ibáñez, F. C.; Marzo, F.; Villarán, M. del C. Microencapsulation of a Probiotic and Prebiotic in Alginate-Chitosan Capsules Improves Survival in Simulated Gastro-Intestinal Conditions. Int. J. Food Microbiol. 2010, 142 (12), 185-189. https://doi.org/10.1016/j.ijfoodmicro.2010.06.022.

(36) Zaeim, D.; Sarabi-Jamab, M.; Ghorani, B.; Kadkhodaee, R. Double Layer CoEncapsulation of Probiotics and Prebiotics by Electro-Hydrodynamic Atomization. LWTFood Sci. Technol. 2019, 110, 102-109. https://doi.org/10.1016/j.lwt.2019.04.040.

(37) Mei, L.; He, F.; Zhou, R. Q.; Wu, C. De; Liang, R.; Xie, R.; Ju, X. J.; Wang, W.; Chu, L. Y. Novel Intestinal-Targeted Ca-Alginate-Based Carrier for PH-Responsive Protection and Release of Lactic Acid Bacteria. ACS Appl. Mater. Interfaces 2014, 6 (8), 5962-5970. https://doi.org/10.1021/am501011j.

(38) Xiao, Y.; Lu, C.; Liu, Y.; Kong, L. L.; Bai, H.; Mu, H.; Li, Z.; Geng, H.; Duan, J. Encapsulation of Lactobacillus Rhamnosus in Hyaluronic Acid-Based Hydrogel for Pathogen-Targeted Delivery to Ameliorate Enteritis. ACS Appl. Mater. Interfaces 2020, 12 (33), 36967-36977. https://doi.org/10.1021/acsami.0c11959.

(39) Sinha, V. R.; Kumria, R. M Icrobially Triggered Drug Delivery to the Colon. Eur. J. Pharm. Sci. 2003, 18, 3-18.

(40) Teoh, P. L.; Mirhosseini, H.; Mustafa, S.; Hussin, A. S. M.; Manap, M. Y. A. Recent Approaches in the Development of Encapsulated Delivery Systems for Probiotics. Food Biotechnol. 2011, 25 (1), 77-101. https://doi.org/10.1080/08905436.2011.547332.

(41) Kurapati, R.; Groth, T. W.; Raichur, A. M. Recent Developments in Layer-by-Layer Technique for Drug Delivery Applications. ACS Appl. Bio Mater. 2019, 2 (12), 5512-5527. 
https://doi.org/10.1021/acsabm.9b00703.

(42) Wang, Q. Z.; Chen, X. G.; Liu, N.; Wang, S. X.; Liu, C. S.; Meng, X. H.; Liu, C. G. Protonation Constants of Chitosan with Different Molecular Weight and Degree of Deacetylation. Carbohydr. Polym. 2006, 65 (2), 194-201. https://doi.org/10.1016/j.carbpol.2006.01.001.

(43) Harris, R.; Lecumberri, E.; Heras, A. Chitosan-Genipin Microspheres for the Controlled Release of Drugs: Clarithromycin, Tramadol and Heparin. Mar. Drugs 2010, 8 (6), 17501762. https://doi.org/10.3390/md8061750.

(44) Chen, S. C.; Wu, Y. C.; Mi, F. L.; Lin, Y. H.; Yu, L. C.; Sung, H. W. A Novel PH-Sensitive Hydrogel Composed of N,O-Carboxymethyl Chitosan and Alginate Cross-Linked by Genipin for Protein Drug Delivery. J. Control. Release 2004, 96 (2), 285-300. https://doi.org/10.1016/j.jconrel.2004.02.002.

(45) Kaur, R.; Gulati, M.; Singh, S. K. Role of Synbiotics in Polysaccharide Assisted Colon Targeted Microspheres of Mesalamine for the Treatment of Ulcerative Colitis. Int. J. Biol. Macromol. 2017, 95, 438-450. https://doi.org/10.1016/j.jibiomac.2016.11.066.

(46) Hobbs, C. A.; Koyanagi, M.; Swartz, C.; Davis, J.; Maronpot, R.; Recio, L.; Hayashi, S. M. Genotoxicity Evaluation of the Naturally-Derived Food Colorant, Gardenia Blue, and Its Precursor, Genipin. Food Chem. Toxicol. 2018, 118, 695-708. https://doi.org/10.1016/j.fct.2018.06.001.

(47) Gorbach, S. L.; Chang, T. W.; Goldin, B. SUCCESSFUL TREATMENT OF RELAPSING CLOSTRIDIUM DIFFICILE COLITIS WITH LACTOBACILLUS GG. The Lancet. De Silva LVK 1987, p 1519. https://doi.org/10.1016/S0140-6736(87)92646-8.

(48) Klein, M. P.; Hackenhaar, C. R.; Lorenzoni, A. S. G.; Rodrigues, R. C.; Costa, T. M. H.; 
Ninow, J. L.; Hertz, P. F. Chitosan Crosslinked with Genipin as Support Matrix for Application in Food Process: Support Characterization and $\beta$-d-Galactosidase Immobilization. Carbohydr. Polym. 2016, 137, 184-190. https://doi.org/10.1016/j.carbpol.2015.10.069.

(49) Tao, S. L.; Popat, K.; Desai, T. A. Off-Wafer Fabrication and Surface Modification of Asymmetric 3D SU-8 Microparticles. Nat. Protoc. 2006, 1, 3153-3158. https://doi.org/10.1038/nprot.2006.451.

(50) Kamguyan, K.; Thamdrup, L. H. E.; Vaut, L.; Nielsen, L. H.; Zor, K.; Boisen, A. Development and Characterization of a PDMS-Based Masking Method for Microfabricated Oral Drug Delivery Devices. Biomed. Microdevices 2020, 22 (2), 35. https://doi.org/10.1007/s10544-020-00490-8.

(51) Christfort, J. F.; Strindberg, S.; Plum, J.; Hall-Andersen, J.; Janfelt, C.; Nielsen, L. H.; Müllertz, A. Developing a Predictive in Vitro Dissolution Model Based on Gastrointestinal Fluid Characterisation in Rats. Eur. J. Pharm. Biopharm. 2019, 142, 307-314. https://doi.org/10.1016/j.ejpb.2019.07.007.

(52) DeSesso, J. M.; Jacobson, C. F. Anatomical and Physiological Parameters Affecting Gastrointestinal Absorption in Humans and Rats. Food Chem. Toxicol. 2001, 39 (3), 209228. https://doi.org/10.1016/S0278-6915(00)00136-8.

(53) Hawksworth, G.; Drasar, B. S.; Hill, M. J. Intestinal Bacteria and the Hydrolysis of Glycosidic Bonds. J. Med. Microbiol. 1971, 4 (4), 451-459. https://doi.org/10.1099/00222615-4-4-451.

(54) Kim, M. S.; Yeom, D. W.; Kim, S. R.; Yoon, H. Y.; Kim, C. H.; Son, H. Y.; Kim, J. H.; Lee, S.; Choi, Y. W. Development of a Chitosan Based Double Layer-Coated Tablet as a 
Platform for Colon-Specific Drug Delivery. Drug Des. Devel. Ther. 2017, 11, 45-57. https://doi.org/10.2147/DDDT.S123412.

(55) Shigemasa, Y.; Saito, K.; Sashiwa, H.; Saimoto, H. Enzymatic Degradation of Chitins and Partially Deacetylated Chitins. Int. J. Biol. Macromol. 1994, 16 (1), 43-49. https://doi.org/10.1016/0141-8130(94)90010-8.

(56) Ravi, V.; Siddaramaiah; Pramod Kumar, T. M. Influence of Natural Polymer Coating on Novel Colon Targeting Drug Delivery System. J. Mater. Sci. Mater. Med. 2008, 19 (5), 2131-2136. https://doi.org/10.1007/s10856-007-3155-x.

(57) Butler, M. F.; Ng, Y. F.; Pudney, P. D. A. Mechanism and Kinetics of the Crosslinking Reaction between Biopolymers Containing Primary Amine Groups and Genipin. J. Polym. Sci. Part A Polym. Chem. 2003, 41 (24), 3941-3953. https://doi.org/10.1002/pola.10960.

(58) Wang, Q. Z.; Chen, X. G.; Liu, N.; Wang, S. X.; Liu, C. S.; Meng, X. H.; Liu, C. G. Protonation Constants of Chitosan with Different Molecular Weight and Degree of Deacetylation. Carbohydr. Polym. 2006, $65 \quad$ (2), 194-201. https://doi.org/10.1016/j.carbpol.2006.01.001.

(59) Liu, Y.; Chen, W.; Kim, H.-I. PH-Responsive Release Behavior of Genipin-Crosslinked Chitosan/Poly(Ethylene Glycol) Hydrogels. J. Appl. Polym. Sci. 2012, 125 (S2), E290E298. https://doi.org/10.1002/app.36899.

(60) Silva, J. M.; Caridade, S. G.; Costa, R. R.; Alves, N. M.; Groth, T.; Picart, C.; Reis, R. L.; Mano, F. PH Responsiveness of Multilayered Films and Membranes Made of Polysaccharides. Langmuir 2015, 49, 37. https://doi.org/10.1021/acs.langmuir.5b02478.

(61) Huang, J.; Zajforoushan Moghaddam, S.; Maroni, P.; Thormann, E. Swelling Behavior, Interaction, and Electrostatic Properties of Chitosan/Alginate Dialdehyde Multilayer Films 
with Different Outermost Layer. Langmuir 2020, 36, 3782-3791. https://doi.org/10.1021/acs.langmuir.0c00330.

(62) Huanbutta, K.; Cheewatanakornkool, K.; Terada, K.; Nunthanid, J.; Sriamornsak, P. Impact of Salt Form and Molecular Weight of Chitosan on Swelling and Drug Release from Chitosan Matrix Tablets. Carbohydr. Polym. 2013, 97 (1), 26-33. https://doi.org/10.1016/j.carbpol.2013.04.073.

(63) Yuan, Y.; Chesnutt, B. M.; Utturkar, G.; Haggard, W. O.; Yang, Y.; Ong, J. L.; Bumgardner, J. D. The Effect of Cross-Linking of Chitosan Microspheres with Genipin on Protein $\begin{array}{llllll}\text { Release. } & \text { Carbohydr. Polym. }\end{array}$ https://doi.org/10.1016/j.carbpol.2006.10.023.

(64) Abid, Z.; Strindberg, S.; Javed, M. M.; Mazzoni, C.; Vaut, L.; Nielsen, L. H.; Gundlach, C.; Petersen, R. S.; Müllertz, A.; Boisen, A.; Keller, S. S. Biodegradable Microcontainerstowards Real Life Applications of Microfabricated Systems for Oral Drug Delivery. Lab Chip 2019, 19 (17), 2905-2914. https://doi.org/10.1039/c9lc00527g.

(65) Zhang, H.; Neau, S. H. In Vitro Degradation of Chitosan by Bacterial Enzymes from Rat Cecal and Colonic Contents. Biomaterials 2002, 23 (13), 2761-2766. https://doi.org/10.1016/S0142-9612(02)00011-X.

(66) Prizont, R.; Konigsberg, N. Identification of Bacterial Glycosidases in Rat Cecal Contents. Dig. Dis. Sci. 1981, 26 (9), 773-777. https://doi.org/10.1007/BF01309607.

(67) Lehr, C. M.; Bouwstra, J. A.; Schacht, E. H.; Junginger, H. E. In Vitro Evaluation of Mucoadhesive Properties of Chitosan and Some Other Natural Polymers. Int. J. Pharm. 1992, 78 (1-3), 43-48. https://doi.org/10.1016/0378-5173(92)90353-4.

(68) Thanou, M.; Verhoef, J. C.; Junginger, H. E. Oral Drug Absorption Enhancement by 
Chitosan and Its Derivatives. Adv. Drug Deliv. Rev. 2001, 52 (2), 117-126. https://doi.org/10.1016/S0169-409X(01)00231-9.

\section{Graphical Abstract}

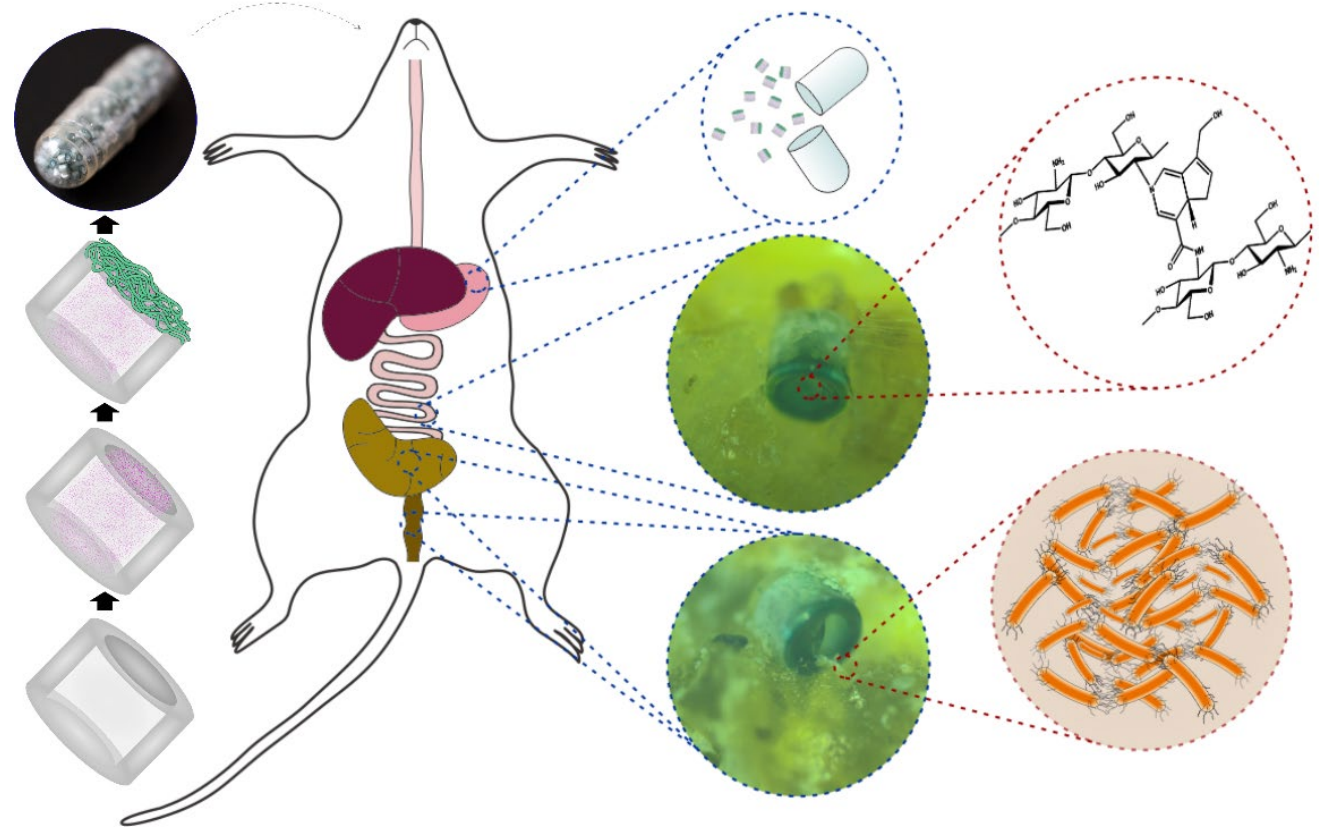

